UDC 811.111'276.6:61

https://doi.org/10.18485/bells.2017.9.1

\author{
Stevan Mijomanović \\ University of Belgrade \\ Faculty of Medicine \\ Belgrade, Serbia
}

\title{
CONCEPTUAL METAPHORS OF ANAESTHESIOLOGY
}

\begin{abstract}
Anaesthesiology is a branch of medicine that enables efficient surgical treatment and the safety of a patient through preoperative treatment, pain relief and monitoring of vital functions during surgical procedures. The aim of this paper is to examine the language of this discipline through the prism of cognitive linguistics. The focus is on the conceptual metaphors and the basic terminology used by anaesthesiologists. Most of the medical terms are of either Greek or Latin origin, and can thus be obscure to laymen. This paper will try to shed some light on the terms used in anaesthesiology by focusing on their etymology. Since pain management is an integral part of anaesthesiology, we will also examine conceptualizations of pain. Medical terminology is closely related to the human body, thus a closer look might reveal how medical professionals perceive it, whether as a machine (e.g. intubation), physical space (local/regional anaesthesia) etc. Identifying conceptual metaphors of medical terminology can give us a broader insight into how and why those who treat us and cure us do what they do. The scope of this study will be restricted to the main processes and phenomena of anaesthesiology
\end{abstract}

Key words: anaesthesiology, the language of medicine, conceptual metaphor, pain.

E-mail: stevan.mijomanovic@gmail.com 


\section{Introduction}

Throughout human history and existence people have tried to solve the riddle of the human body. We have tried to understand and give meaning to what we feel, how we experience the world around us and the world inside us. Ancient peoples had different ideas about the working of the human body, ranging from a set of tubes permeating our body, parts of the body being under the auspices of different deities (Egypt), or the Hippocratic theory of the entire body being an equilibrium of four humours (blood, black bile, yellow bile, phlegm). Since then, our knowledge has grown and is still growing. We are now aware of the minute mechanisms that set the body and life in motion, we know about various diseases, numerous medicines and techniques that prolong our life span, and we are still learning and discovering. This progress has led to the emergence of genetics, enzymology, molecular biology, biophysics, biochemistry, and a large number of clinical branches; internal medicine alone has ramified into cardiology, gastroenterology and hepatology, endocrinology, etc. (Micic 2008:10). But with all this progress, we have encountered numerous concepts, phenomena and different insights that needed to

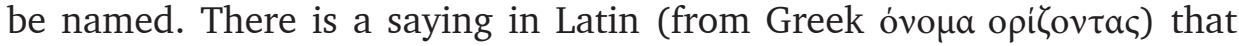
usually refers to humans -nomen est omen - however, it can be applied to words. Each word has its denotation and connotation. The language of medicine is not different in this respect and is, as the above-mentioned saying, rooted in both Greek and Latin. "The language of medicine rests on a fundamentally learned terminology made up of formants (roots, prefixes, suffixes) drawn from Greek and Latin" (Van Hooff 1998: 49). Some of these words have entered the everyday language and are understandable to a majority of people (tumour, coagulation), whereas some are completely indecipherable to a laymen (endocarditis, elastofibroma). The language of medicine begs for implicit knowledge in order for it to be comprehensible and thus it stays mostly bound to medical and healthcare professionals. Medical language tends to describe rather than define the incompletely fathomed natural phenomena (Rothwell et al. 1994: 695). This paper will try to unveil the covert meanings of the terminology of one of the most comprehensive branches of medicine, i.e. anaesthesiology. This will be done through a cognitive framework, mainly focusing on etymology through the prism of the conceptual metaphor theory. The aim is to further understand how we and medical and healthcare professionals perceive our 
Stevan Mijomanović: Conceptual Metaphors of Anaesthesiology

bodies. Studying the underlying conceptual metaphors of anaesthesiology can give us the starting point for further research of conceptual metaphors of all branches of medicine. This can further help us understand the limits of our knowledge and contribute to the progress of medical sciences.

\section{Anaesthesia}

Anaesthesia is reaching the alleviation or absence of pain and sense of touch, with or without loss of consciousness. An anaesthesiologist is a specialist who applies various technical procedures and medicines to induce patients into anaesthesia. The primary role of an anaesthesiologist is to ensure that the patient experiences anaesthesia painlessly and safely. Anaesthesiology is a branch of medicine that is being developed with the aim of increasing the efficacy of surgical treatment, the safety of a patient, and with the aim of minimizing and annihilating the suffering caused by pain and psychological tension in patients.

Most people, when asked about the role of an anaesthesiologist, will say that this is a doctor that puts you to sleep. The role of anaesthesiologists is, however, far more complex than this. During surgery, an anaesthesiologist is the one who monitors all your vital functions (your temperature, blood pressure, your heart, lung and kidney function) and, if need be, tends to any disturbances, makes up for lost blood and fluids and regulates the dosage of the medication to ensure complete absence of pain during and after the operation. An anaesthesiologist, simply put, keeps you alive during an operation. In order to do this, an anaesthesiologist must have an extensive knowledge of physiology, pathophysiology, pharmacology, surgical diseases and their basic treatments, pain therapy, reanimation and resuscitation, and principles of intensive and critical care. Without anaesthesia, modern medicine, as we know it today, would not be possible. Many procedures could not be done without the patient being completely senseless. Anaesthesia ensured that patients do not die from both physical and psychological trauma, and it made the advancement of medicine possible. Today's innovation and improvement of new surgical techniques and procedures owe their existence to anaesthesia. Bearing all of the abovementioned in mind and the extensiveness of knowledge needed to practise it, we are of the opinion that the terminology of anaesthesia would be the best starting point of a linguistic study concerned with the conceptual metaphors of medical terminology. 


\section{Metaphors of medicine}

Metaphor is a powerful tool that gives form to many abstract concepts and phenomena that we experience. The way we think, i.e. our cognition, is embodied. The structure of our thoughts stems from our bodies and what our bodies experience (Lakoff and Johnson 1980). The pervasiveness of metaphor, metaphorical mappings from more concrete source domains to more abstract target domains, in everyday life and thought have been widely explored in many areas of human knowledge. Medicine is no exception. We have already mentioned different perceptions of the human body throughout human history. Naturally, with the evolution of that knowledge, we grasped for words and concepts that would give shape to a rapidly growing understanding of the world around us and inside us. One of the main mechanisms of production of new words of science and medicine is meaning extension via metaphor. According to Fleishman (2006: 484) there is a spectrum of researches dedicated to either metaphors of medicine or metaphors based on the human body. These explorations range from the metaphoric language of pain, metaphors of destruction and purgation, moral and cultural implications of metaphors, metaphors in doctor-patient communication, and metaphors generated by body parts and their afflictions. Semino (2008) has focused on metaphors in educational materials and scientific metaphors through many examples of medical texts. She has also focused on the metaphors of cancer, their identification and usage by the patients (Semino et al. 2004; 2015). Other researchers, such as Ning Yu (2003) and Judit Simó (2011), have looked at certain body parts, the gallbladder and blood respectively, and the cultural boundedness of the metaphors they generate. On the level of texts, medical and scientific metaphors have been explored by Van Rijn-van Tongeren (1997) and Cameron (2003).

Van Rijn-van Tongeren (1997: 57) says that many theorists make a distinction between 'dead' and 'live' metaphors. Dead metaphors are idioms that were once used in everyday language, but have become petrified over time, i.e. conventionalized and fixed in the lexicon. She argues that, because of this, many authors find the 'live' metaphors more worthy of analysis due to the greater chance of creative interpretation. According to her, many 'dead' metaphors are not even recognised as metaphors, and she explains this phenomenon referring to Black, who states that this happens in the cases of catachresis (use of a word in a new sense in order to fill 
in the gap in the lexicon). In opposition to Black, Van Rijn-van Tongeren mentions Searle as being the proponent of 'dead' metaphors, as they are the ones that survived.

Van Rijn-van Tongeren sees metaphors as surface representations of an underlying conceptual system and she identifies 1 . metaphors used to structure medical concepts and 2. functions of metaphorical expressions in medical texts. She differentiates between three different functions: catachretic, didactic and theory-constitutive (Van Rijn-van Tongeren 1997: 97-103). Catachrectic metaphors fill in the gaps in the vocabulary ('blood vessels as rivers'), didactic metaphors explain new concepts by means of new concepts ('the body is a machine'), and theory-constitutive metaphors are applied to phenomena that are still unknown in order to structure it.

Similar to Van Rijn-van Tongeren, Cameron (2003: 200-2) discusses a passage from a science textbook aimed at schoolchildren and identifies three different kinds of metaphorical expressions: technical, technical + theory, and sub-technical. Technical metaphors are conventionalized terms within the scientific domain ('chambers' and 'walls'), while sub-technical metaphors have a pedagogic potential (blood as the body's 'transport system') in explaining certain phenomena as opposed to theory-constitutive use.

Lakoff (1993) argues that the term 'metaphor' refers to "a cross-domain mapping in the conceptual system", and the term 'metaphorical expression' refers to "a linguistic expression (a word, a phrase, or sentence) that is the surface realisation of such a cross-domain mapping". In this paper we will examine the terminology of anaesthesia and, in that respect, we will focus mainly on metaphorical expressions such as words and phrases, and on their underlying cross-domain mappings. Our focus will also be more on dead metaphors, since most terms in medical terminology represent an already set lexical system, and we will concentrate on the catachrectic or technical metaphors.

\section{Anaesthesia and sedation metaphors}

According to The Oxford English Dictionary (OED) anaesthesia is [an(Greek: not/without) + aisthesis (Greek: to feel/perceive)] want of feeling/ sensation; insensibility. Anaesthesia is a combination of medications that block pain and other sensations and, at times, leads to the state of unconsciousness (general anaesthesia). General anaesthesia includes a 
state of manageable reversible unconsciousness, amnesia and analgesia. ${ }^{1}$ When a person is under general anaesthesia, unconsciousness is followed by inactivity and lack of perception. The underlying conceptual metaphor is CONSCIOUS IS ACTIVE/PERCEPTION. Another conceptual metaphor that follows, CONSCIOUS IS UP> ACTIVE IS UP, can be seen in phrases such as to be/go under or undergo (general) anaesthesia.

There are many different types of anaesthesia, but we will focus on the main ones, which also serve as the umbrella terms for the more specific ones. According to the scope of its effect, anaesthesia can be general, regional and local. General anaesthesia means that there is absence of pain over the entire body. In the OED general is defined as involving or including all, or nearly all, the parts of a specified whole. Its second meaning is to be concerned with the whole of a certain territory or an organisation, as opposed to local. Regional anaesthesia is absence of pain over a portion of the body, such as an arm or leg. Regional is defined in the OED as something pertaining to a district, portion of a country, territory, district. Local anaesthesia is absence of pain over a small area of the body. Local according to the OED is pertaining to a 'place' or a position in space. Its second meaning is belonging to a particular place on the Earth's surface; pertaining to a particular region or district. From the definitions above, we can see that the human body is perceived topographically, so the underlying conceptual metaphor here is the HUMAN BODY IS A GEOGRAPHIC SURFACE/TERRITORY.

The medicines used in anaesthesiology roughly fall into the following groups: hypnotics, sedatives, analgesics and muscle relaxants. Analgesics can be opioids or non-opioids. Another term for analgesics is narcotics. It is nowadays being used less and less by anaesthesiologists, due to the fact that it has entered jargon and now usually denotes addictive, usually illegal, drugs. The terms used for these anaesthetics hide in them a conceptual metaphor, CONSCIOUS IS ACTIVE. Hypnotics produce hypnosis, or artificially induced sleep (OED). Narcotics cause narcosis, from Greek narkosis, from narkoun, to benumb, or a state of insensibility (OED). Sedatives induce sedation, from Latin sedatus 'composed, moderate, quiet, tranquil,' past participle of sedare 'to settle, calm', causative of sedere 'to sit'; the act of making calm (OED). The conceptual metaphor CONSCIOUS IS ACTIVE is seen in the etymology of these words where one is asleep, sitting or benumbed. Insensibility, which permeates these definitions, also leads

1 http://www.anesthesiazone.com/anesthesia-glossary.aspx 
us to another conceptual metaphor: PERCEPTION IS ACTIVE. Analgesics and analgesia will be discussed later in the section dedicated to pain.

Sedation has several levels: anxiolysis, moderate and deep sedation, and general anaesthesia. Anxiolysis, or minimal sedation, "is a level of sedation that relieves anxiety but preserves consciousness" ${ }^{2}$. Moderate sedation "is a level of sedation that depresses consciousness and relieves anxiety and pain". Deep sedation "is a level of sedation in which the patient is not easily aroused, but responds purposefully to repeated or painful stimulation". ${ }^{3}$ Finally, general anaesthesia, as previously mentioned, "is when the patient is completely unconscious, and not responsive to painful stimuli."" The key word here is the word level. As the level of the anaesthetic increases, the level of consciousness decreases, almost as if it is being pushed out gradually. The underlying conceptual metaphor is CONSCIOUSNESS IS A SUBSTANCE. Since our consciousness is governed by our brain/mind, another implied conceptual metaphor is MIND IS A SUBSTANCE, and, as Lakoff and Johnson (1980) have already observed, this takes us to the conclusion that the HUMAN BODY IS A CONTAINER.

\section{Pain metaphors}

Human kind has always searched for a way not to feel pain and anaesthesia, at least when it comes to medical procedures, has achieved this. The basic goal of any kind of anaesthesia is for the patient not to feel pain, to be benumbed, insensible, i.e. to reach the state of analgesia, painlessness (OED). In this part of the paper, we will focus on the conceptualisation of pain.

The examples have been gathered from a myriad of online articles about anaesthesia. We searched for the word pain in these articles and observed its collocations.

The first conceptual metaphor is already obvious in one of the main goals of anaesthesia, which is to reach the state where one does not feel pain, i.e. analgesia (painlessness). Analgesic/analgetic is tending to remove pain, or a medicine that removes pain (OED). The conceptual metaphor

2, http://www.psanes.org/Legislators/TypesofAnesthesia/tabid/207/Default.aspx

3 Ibid.

4 Ibid. 
hidden in these terms is PAIN IS A HEAVY OBJECT/ENTITY. Other examples of the realisation of this conceptual metaphor are phrases such as heavy pain and pain relief. The latter example is slightly more obscure. To relieve comes from Latin relevare 'to raise, alleviate, lift up, free from a burden', from re-, intensive prefix, + levare „to lift up, lighten, “ from levis 'not heavy' (OED).

Another conceptualisation of pain actually stems from its physical aspect. When a tissue is damaged, actually or potentially, it releases energy. We describe this process as pain and usually modify it with adjectives such as burning or searing, which leads us to the following conceptualisation of pain, PAIN IS HEAT.

One of the most common ways of describing pain discloses yet another conceptual metaphor. Expressions such as stabbing pain, dull or sharp pain, acute pain, lancinating pain and piercing pain all have one quality in common. They are all experienced as a sensation of being cut or pierced by a knife, needle, etc. The conceptual metaphor behind these expressions is PAIN IS A CUTTING/PIERCING INSTRUMENT.

When we feel pain, we usually become completely immersed in the sensation. It can have such an effect on us that at times it can render us senseless, or in extreme situations, even lead to a fatal outcome. Anaesthesia makes it its primary goal to regulate the level of pain we experience, thus we have pain management and pain control. These two phrases reveal a conceptual metaphor rooted in the animal world. To manage is to handle, train or direct, control, cause to submit to one's rule (of persons and animals) (OED). The same conceptual metaphor behind these is also hidden in the expressions such as gnawing pain and intractable pain. Intractable relates to persons and animals that are not to be guided; not docile or manageable (OED). An anaesthesiologist's task is to tame this pain, to make it yield to the power of anaesthetics; hence we see that the underlying conceptual metaphor is PAIN IS A WILD ANIMAL/BEAST.

MEDICINE IS WAR (Sontag 1977; Hodgkin 1985) is a well-known metaphor. However, if we say that the metaphor is ANAESTHESIOLOGY IS WAR, then we a have a new conceptualisation of pain. In the previous paragraph, we said that anaesthesiology tamed pain, however, in the following expressions we will see that it also battles pain. In order to fight/ block (violent) pain we use painkillers, thus we have another conceptual metaphor, PAIN IS AN OPPONENT/ENEMY.

Finally, pain is something we can describe as scalar quantity. In the expressions pain assessment (the determination or adjustment of the amount 
of taxation, charge, fine etc. /OED/) and pain level we can recognise the underlying conceptual metaphor where PAIN IS A RESOURCE, or taken to a more concrete level, PAIN IS A SUBSTANCE.

\section{Other metaphors}

During surgery or any invasive procedure, anaesthesiologists are the ones who pay attention to our heart rate, blood pressure, temperature, levels of oxygen in our blood and tissues, the depth of anaesthesia, heart, lung and kidney functions, etc. In order for the patient to wake up safely and unharmed, anaesthesiologists have to know about his/her health condition. They asses the risks, choice of anaesthetics, and the possible need for further diagnostic and therapeutic procedures with the aim of optimizing the patient's condition for the upcoming intervention. Anaesthesiologists use many drugs which can be toxic, depending on the dosage, or cause allergies. They also apply various invasive methods, which, in order to be efficient, disturb the integrity of the patient's body. Anaesthesia in itself is an artificially induced state that has many attendant risks. Sometimes, during a procedure, even with the expertise of both the anaesthesiologist and the surgeon, complications arise. The most extreme complications can lead to cardiac arrest, and then anaesthesiologists resort to reanimation and resuscitation.

To resuscitate is to revive, restore; from Latin resuscitatus, past participle of resuscitare, rouse again, revive, from re- 'again' + suscitare 'to raise, revive' (OED). To reanimate in a spiritual and physical sense, from re- (back, again) + animate (to endow with life) (OED). Even though both actions refer to bringing someone back to life, the underlying conceptual metaphors are different. In resuscitation the metaphor is LIFE IS UP, and in reanimation it is LIFE IS A GIFT. From the latter, we can deduce an even more concrete metaphor, LIFE IS AN ENTITY/OBJECT.

To minimize the adverse effects of both anaesthesia and surgery, an anaesthesiologist keeps track of the patient's vital functions and maintains anaesthesia. In the expression maintenance of anaesthesia we can see the underlying conceptual metaphor COUSCIOUSNESS IS A MACHINE, which further on implies that MIND IS A MACHINE. Since, both consciousness and the mind are situated in our body, they are both cogs of a larger machine. The HUMAN BODY IS A MACHINE metaphor is also discernible in the phrase monitoring of vital functions. 
We have already mentioned the metaphor HUMAN BODY IS A CONTAINER; however, in the following example we will see its more specific realisation. Namely, throughout anaesthesia one of the most important factors is maintenance of normal breathing. This process is called ventilation. Ventilation is oxygenation of the blood through respiration. Ventilation is defined as a stir or motion of the air, and its fourth meaning is the admission of a proper supply of fresh air, esp. to a room, building, mine etc. (OED). This expression conceals the conceptual metaphor HUMAN BODY IS A BUILDING. This metaphor tells us how we perceive the body as a structured, sturdy entity that contains multiple compartments and could serve as a place of inhabitation.

The last metaphor is related to the practitioner of anaesthesiology, but can refer to other physicians as well. After the initial examination and assessment, an anaesthesiologist induces anaesthesia. To induce is to lead into, introduce, or bring in (OED). Through this, an anaesthesiologist leads us into unconsciousness. There are two underlying metaphors in this setting; AN ANAESTHESIOLOGIST/DOCTOR IS A GUIDE which then further implies CONSCIOUSNESS/UNCONSCIOUSNESS IS A JOURNEY.

\section{Conclusion}

Lakoff and Johnson (1980) observed that metaphors 'highlight and hide' certain aspects of a phenomenon, while other aspects are in the background or entirely obscured. If we take the conceptual metaphor HUMAN BODY IS A MACHINE as an example, we can see that we perceive the body as a set of mechanisms that can be controlled by humans. It also implies that we understand the workings of the human body in its entirety, since machines are manmade. What is omitted in this kind of conceptualization of the human body is our lack of comprehensive knowledge of its functioning and the fact that it is governed by natural laws. (Fleishman 2006: 489). Similarly, the conceptual metaphor HUMAN BODY IS A GEOGRAPHIC SURFACE/ TERRITORY highlights the governable portions of our bodies. This implies that the body is divided into sections and that the healing process can be successfully executed if we tend to the infected/afflicted area. However, we know that the body is an intricate system of interrelations of structures and connections. These kind of conceptualisations, though limited, have a very important role in medicine. Physicians are able to orientate better and 
focus on the specific areas that need to be tended. However, they have to be aware of the human body as a whole. Their education does offer them this kind of knowledge. Through their education they learn countless new words and concepts. These words and concepts on their own are useless, but together they make a model that has, thus far, proven to be effective in the treatment of many illnesses, diseases and traumas. And this model is constantly evolving. This model is also visible on the level of conceptual metaphors. The conceptual metaphors CONSCIOUS IS UP> ACTIVE IS UP, CONSCIOUSNESS IS A SUBSTANCE, and the HUMAN BODY IS A CONTAINER are, at least when talking about anaesthesia, very much connected. Once we are injected with an anaesthetic, e.g. when we are going under general anaesthesia, our consciousness is 'being depressed/ pushed down and out' of our body, rendering us senseless (typically, this leads to a lying position).

Some metaphors exclude other possible ways of perceiving the human body, health and illness. On the discourse level, Fuks (2009; 57-68) believes that the WAR metaphor is gradually being replaced by metaphors of renewal, springtime and bloom. Similarly, Hodgkin (1985) suggests alternative metaphors, such as, BODY IS A BIOCHEMICAL DANCE and MEDICINE IS COLLABORATIVE EXPLORATION. Furthermore, genetics is a field of medicine that has been evolving rapidly recently and is giving us new insights into the functioning of the body, and with them new conceptualisations. Semino (2008: 151) observes that DNA is being described via an INSTRUCTIONS metaphor, a part of the LANGUAGE/ COMMUNICATION metaphor, used for theory constitutive purposes since the early days of genetics. These alternatives and new emerging terminology might be a herald of a new era in which the idea of our bodies, health and illnesses will change.

The metaphors of anaesthesiology that we identified show us how physicians, at least in this branch of medicine, perceive consciousness and the mind as something tangible, as substances, something that we can manipulate. Only time will tell to what extent this is true.

Pain is regarded as something dangerous, wild and invasive. Expressions focused on pain fail to express what medicine has known for a very long time, that pain, even though unpleasant, is the body's reaction that signals to us when something is wrong, and is actually positive and sometimes lifesaving. If we changed our view of pain, the way it is treated and experienced could change as well. The conceptualisation seen in 
the expressions pain assessment and pain level, PAIN IS A RESOURCE/ SUBSTANCE, could be a starting point.

The human body is complex and still not entirely understood. Medicine is, however, galloping towards new discoveries every day. The language of medicine has to rediscover itself daily in order to keep up with the advancements. The existing medical terms do have their limitations, but if observed in isolation. When they are a part of a larger conceptual model, they fit into the puzzle that is our knowledge and comprehension of ourselves. New findings, innovations and information gradually infiltrate terminology and complement the idea that is the human being.

\section{References}

Anesthesiazone.com (16 October 2015) < http://www.anesthesiazone. com/anesthesia-glossary.aspx $>$

Cameron, L. (2003). Metaphor in Educational Discourse. A\&C Black.

Fleischman, S. (2001). Language and medicine. The Handbook of Discourse Analysis, 470-502.

Fuks, A. (2009). The military metaphors of modern medicine. The Meaning Management Challenge, 124, 57-68.

Hodgkin, P. (1985). Medicine is war: and other medical metaphors. Br Med $J$ (Clin Res Ed), 291(6511), 1820-1821.

Lakoff, G. (1993). The contemporary theory of metaphor. In: Ortony, A. (Ed.), Metaphor and Thought, second ed. Cambridge University Press, Cambridge, pp. 202-251.

Lakoff, G., \& Johnson, M. (2008). Metaphors We Live By. University of Chicago press.

Mićić, S. (2009). Studije o jeziku medicine u engleskom i srpskom. Beograd: Beogradska knjiga, 92-94.

Oxford English Dictionary (1993) Oxford: Clarendon Press.

Pennsylvania Society of Anesthesiologists, Physicians Protecting Partients (16 October 2015) <http://www.psanes.org/Legislators/ TypesofAnesthesia/tabid/207/Default.aspx\# >

Rothwell, D.J. et al. (1993). Developing a standard data structure for medical language - the SNOMED proposal. In Proceedings of the Annual Symposium on Computer Application in Medical Care (p. 695). American Medical Informatics Association. 
Semino, E. et al. (2004). Methodological problems in the analysis of metaphors in a corpus of conversations about cancer. Journal of Pragmatics, 36(7), 1271-1294.

Semino, E. (2008). Metaphor in Discourse. Cambridge: Cambridge University Press.

Semino, E. et al. (2015). The online use of Violence and Journey metaphors by patients with cancer, as compared with health professionals: a mixed methods study. BMJ supportive \& palliative care, bmjspcare-2014.

Simó, J. (2011). Metaphors of blood in American English and Hungarian: A cross-linguistic corpus investigation. Journal of Pragmatics, 43(12), 2897-2910.

Sontag, S. and Broun, H. H. (1977). Illness as Metaphor (p. 343). Center for Cassette Studies.

Van Hoof, H. (1998). Ministudy of English and French. Translation and Medicine, 49.

Van Rijn-van Tongeren, G. W. (1997). Metaphors in Medical Texts (Vol. 8). Rodopi.

Yu, N. (2003). Metaphor, body, and culture: The Chinese understanding of gallbladder and courage. Metaphor and Symbol, 18(1), 13-31. 